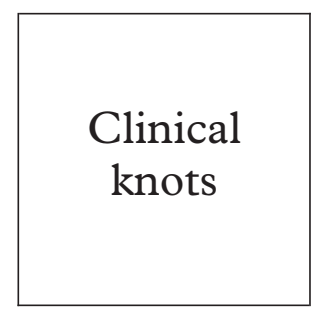

\section{Is cytomegalovirus viraemia a useful tool in managing CMV disease?}

\author{
Jane R Deayton
}

HIV related cytomegalovirus (CMV) disease results from reactivation of latent infection when the CD4 count falls below 100 cells $\times 10^{6} / 1$. Before the introduction of highly active antiretroviral therapy (HAART) up to $40 \%$ of HIV infected patients developed CMV disease, predominantly retinitis. Early diagnosis of retinitis may result in a better response to therapy and reduced loss of vision. As retinitis is often asymptomatic in the early stages, other methods of identifying individuals at risk are required.

CMV viraemia precedes disease so the detection of CMV viraemia identifies individuals at highest risk. Cell culture based methods of detection have now been superseded by polymerase chain reaction (PCR) and pp65 antigenaemia assays. The application of quantitative techniques has shown that elevated CMV load increases the risk of CMV disease in congenital infection ${ }^{1}$ and following renal, ${ }^{2}$ liver, ${ }^{3}$ and bone marrow ${ }^{4}$ transplantation.

\section{Identification of patients at risk of CMV disease}

The detection of CMV reactivation by polymerase chain reaction (PCR) is a strong predictor of disease..$^{5-7}$ CMV load is significantly higher in patients who develop disease and the risk of disease increases with increasing CMV load; high CMV load also correlates with decreased survival. ${ }^{5}$ Two large randomised controlled trials of CMV prophylaxis showed that CMV PCR positivity at baseline is a significant risk factor for CMV disease and is associated with an increased risk of death independent of CD 4 count. ${ }^{89}$ In addition, CMV load has a stronger correlation with death than HIV load. ${ }^{10}$ Therefore, regular screening of patients with a CD4 count below 100 cells $\times 10^{6} / 1$ by CMV PCR can identify those at highest risk of CMV disease and death. This allows for interventions to prevent development of disease or to optimise early diagnosis and treatment.

Department of Virology, Royal Free and University College Medical School, Royal Free Campus,

Rowland Hill Street, London NW3 2PF, UK J R Deayton

Correspondence to: j.deayton@rfc.ucl.ac.uk

Accepted for publication 18 July 2000

In the absence of anti-CMV therapy, CMV load continues to increase with progression of CMV disease up to the time of death. ${ }^{11}$ Treatment with anti-CMV therapy results in a decline in CMV load, usually to undetectable. ${ }^{12}$ Patients with high CMV load at diagnosis of retinitis are less likely to respond to induction therapy and have a decreased time to first progression. ${ }^{12}$ Response to anti-CMV treatments can therefore be monitored and induction therapy should ideally be continued until
CMV PCR is negative. Failure to suppress CMV viraemia in a previously treated individual should raise the possibility of drug resistance and prompt consideration of treatment with an alternative agent.

\section{Monitoring of patients on maintenance therapy}

In a study of patients receiving ganciclovir maintenance for retinitis, recurrent CMV PCR positivity and increasing CMV load were observed before progression of retinitis. ${ }^{13}$ Recurrent CMV viraemia was also associated with the development of CMV disease at other sites. Regular screening of patients on maintenance therapy by PCR can therefore be recommended. The recurrence or persistence of CMV viraemia is an indication for systemic anti-CMV treatment in addition to local therapy (intraocular injection or implant) to reduce the risk of extraocular disease.

\section{Prophylaxis and pre-emptive therapy}

Spector et al reported that prophylaxis with oral ganciclovir reduced the incidence of CMV disease to $16 \%$ from $30 \%$ in the placebo group. ${ }^{14}$ Subgroup analysis by baseline CMV PCR status showed that the lowest incidence of disease was seen in patients with negative CMV PCR or low CMV loads. This suggests that early treatment of low level CMV viraemia with oral ganciclovir is effective and reduces risk of disease development. However, this is inadequate for those with high CMV loads and alternative drugs with better oral bioavailability, such as valaciclovir, are required. ${ }^{15}$ Another prodrug, valganciclovir, was as efficacious as intravenous ganciclovir in a trial of induction therapy for CMV retinitis and is therefore also an attractive agent for use as prophylaxis. ${ }^{16}$

The approach of directing treatment to patients at highest risk is termed pre-emptive therapy and offers a logical way of reducing CMV disease while avoiding drug related adverse events in those at low risk. However, the need for such strategies has decreased following the widespread introduction of HAART.

\section{Effect of HAART on CMV disease}

The studies quoted above were conducted before the widespread use of HAART. The death rate from AIDS and the incidence of all opportunistic infections, including CMV, has declined dramatically since the introduction of HAART. ${ }^{17}$ The survival of patients following CMV retinitis has increased and the risk of relapse has decreased following HAART. ${ }^{18} 19$ 


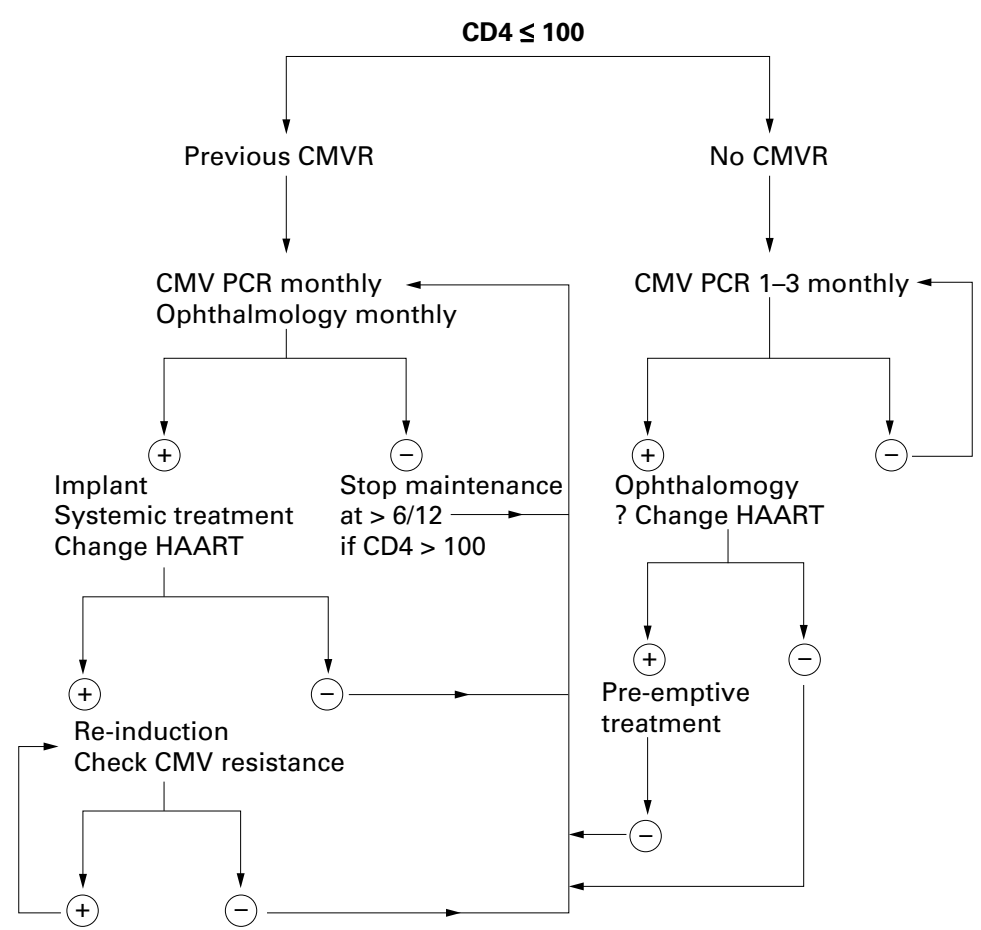

Figure 1 Suggested management of patients on HAART using CMV PCR. CMVR = CMV retinitis, + = CMV PCR positive, $-=C M V P C R$ negative.

There are reported cases of CMV retinitis resolution with HAART alone. ${ }^{20}{ }^{21}$ However, recent reports describe the development of inflammatory complications of retinitis, such as vitritis, following HAART. ${ }^{22}{ }^{23}$ This has been attributed to immune reconstitution and may cause significant loss of vision in the absence of active retinitis.

\section{Monitoring of patients on HAART}

A study of patients with asymptomatic CMV viraemia at the time of initial HAART demonstrated clearance of CMV viraemia following HAART in the absence of specific anti-CMV therapy. ${ }^{24}$ This was sustained for a median of 21 months of follow up and correlated with a greatly reduced risk of CMV disease. In a study of patients with low CD4 counts commencing HAART, CMV PCR positivity at baseline was the only factor associated with the development of CMV disease. ${ }^{25}$ The risk was greatest in those with the highest CMV loads and most cases occurred in the first 90 days of HAART. Identification of patients who are CMV PCR positive at the time of initiation of HAART is therefore important, as they will require careful monitoring for CMV disease. Pre-emptive treatment for CMV may be considered before HAART, especially if the CMV load is high. At our hospital all patients who have ever had a CD4 count of 100 cells $\times 10^{6} / 1$ or less undergo continued monitoring for CMV by PCR as part of a trial protocol. However, it would be reasonable to discontinue this if the CD4 count is sustained above this for more than 6 months; monitoring should be reintroduced if there is a subsequent decline in the CD4 count.

\section{Maintenance therapy for $\mathrm{CMV}$ retinitis in} patients on HAART

Several studies have shown that maintenance therapy for CMV retinitis can safely be withdrawn in selected patients following successful HAART. ${ }^{26-30}$ Using the criteria applied in these studies, discontinuation of maintenance may be considered if there is inactive retinitis after more than 6 months of HAART, the CD4 count has increased above 100 cells $\times 10^{6} / 1$, there is an undetectable HIV load (or greater than $1 \log _{10}$ reduction in HIV load), and an absence of CMV viraemia. It is nevertheless important that individuals discontinuing maintenance therapy are monitored closely. Recurrence of CMV viraemia should prompt review of the patient's therapy, as this may be an early indicator of antiretroviral failure. The risk of CMV disease appears to be re-established if the CD4 count falls again following HAART failure or interruption. ${ }^{31}{ }^{32}$ In this situation consideration should be given to the alteration or intensification of HAART and to the reinstitution of anti-CMV therapy.

It is unclear how long the impact of HAART may be sustained and there is concern that HAART failure will be accompanied by a re-emergence of opportunistic infections. CMV PCR therefore remains an important tool in monitoring patients in this era of rapidly changing therapy for HIV. Figure 1 shows our current investigational algorithm for monitoring patients on HAART with CMV PCR. However, this may require modification as treatments progress and, to this end, monitoring of these patients is continuing.

I would like to thank Professor PD Griffiths, Professor VC Emery, Dr MA Johnson, Dr P Wilson, and Miss CC Davey for their support in my studies and help in preparation of this paper. My work is funded by a Medical Research Council Training Fellowship.

1 Stagno S, Reynolds DW, Tsiantos A, et al. Comparative serial virologic and serologic studies of symptomatic and subclinical congenitally and natally acquired cytomegalovirus infections. F Infect Dis 1975;132:568-77.

2 Cope AV, Sweny P, Sabin C, et al. Quantity of cytomegalovirus viruria is a major risk factor for cytomegalovirus disease after renal transplantation. $\mathcal{F}$ Med Virol 1997;52:200-5.

3 Cope AV, Sabin C, Burroughs A, et al. Interrelationships between quantity of cytomegalovirus DNA in blood, donor/recipient status and augmented prednisolone as risk factors for HCMV disease following liver transplantation. $\mathcal{F}$ Infect Dis 1997;176:1484-90.

4 Gor D, Sabin C, Prentice HG, et al. Longitudinal fluctuations in cytomegalovirus load in bone marrow transplant recipients: Relationship between peak virus load, donor/recipient serostatus, GVHD and CMV disease. Bone Marrow Transplantation 1998;21:597-605.

5 Bowen EF, Sabin CA, Wilson P et al. Cytomegalovirus viraemia detected by polymerase chain reaction identifies a group of HIV-positive patients at high risk of CMV disease. Aroup of HIV-positive $1997 ; 11: 889-93$.

6 Shinkai M, Bozette SA, Powderly W et al. Utility of urine and leukocyte culture and plasma DNA for identification of HIV patients at risk for human CMV disease. F Infect Dis 1997;175:502-8.

7 Dodt KK, Hoy Jacobson P, Hoffman B. Development of CMV disease may be predicted in HIV-infected patients by CMV PCR and the antigenaemia test. AIDS 1997;11:F218.

8 Spector SA, Wong R, Hsia K, et al. Plasma CMV DNA load predicts CMV disease and survival in AIDS patients. $\mathcal{F}$ Clin Invest 1998;101:497-502.

9 Emery VC, Sabin C, Feinberg JE, et al. Quantitative effects of valaciclovir on the replication of cytomegalovirus in persons with advanced human immunodeficiency virus disease: baseline CMV load dictates time to disease and disease: baseline CMV load dict
survival. fID 1999;180:695-701.

10 Spector SA, Hsia K, Crager M, et al. Cytomegalovirus DNA load is an independent predictor of CMV disease and survival in advanced AIDS. F Virol 1999;73:7027-30. 
11 Bowen EF, Sabin CA, Atkins M, et al. Natural history of untreated cytomegalovirus retinitis. Lancet 1995;346: untreated

12 Bowen EF, Sabin CA, Wilson P, et al. Cytomegalovirus retinitis in AIDS patients: influence of cytomegaloviral load on response to ganciclovir, time to recurrence and survival. AIDS 1996;10:1515-20.

13 Bowen EF, Emery VC, Wilson P, et al. Cytomegalovirus polymerase chain reaction viraemia in patients receiving ganciclovir maintenance therapy for retinitis. AIDS 1998; 12:605-11.

14 Spector SA, McKinley G, Lalezari JP, et al. Oral ganciclovir for the prevention of cytomegalovirus disease in persons with AIDS. N Engl f Med 1996;334:1497-7.

15 Feinberg JE, Hurwitz S, Cooper D, et al. A randomized, double-blind trial of valaciclovir prophylaxis for CMV disease in patients with advanced human immunodeficiency virus infection. F Infect Dis 1998;177:48-56.

16 Martin D, Sierra-Madero J, Walmsley S, et al Valganciclovir vs intravenous ganciclovir as induction therapy for newly diagnosed cytomegalovirus retinitis: a randomized, controlliagnosed cytomegalovirus retinitis: a randomized, controlled study. Abstract 231, 7th Conference on Retroviruses and Oppo

17 Palella FJ, Delaney KM, Moorman AC, et al. Declining morbidity and mortality among patients with advanced human immunodeficiency virus infection. $N \mathrm{Engl} F \mathrm{Fed}$ 1998;338:853-60.

18 Walsh JC, Jones CD, Barnes EA, et al. Increasing survival in AIDS patients with cytomegalovirus retinitis treated with combination antiretroviral therapy including HIV protease inhibitors. AIDS 1998;12:613-18.

19 Deayton JR, Wilson P, Sabin CA, et al. Changes in the natural history of cytomegalovirus retinitis following the introduction of highly active antiretroviral therapy. AIDS 2000;14:1163-70.

20 Whitcup SM, Fortin E, Nussenblatt RB, et al. Therapeutic effect of combination antiretroviral therapy on cytomegaloeffect of combination antiretroviral therapy
virus retinitis. $¥ A M A$ 1997;277:1519-20.

21 Reed JB, Schawb IR, Gordon J, et al. Regression of cytomegalovirus retinitis associated with protease-inhibitor treatment in patients with AIDS. Am $\mathcal{f}$ Ophthalmol 1997;124:199-205.

22 Karavellas MP, Lowder CY, Macdonald C, et al. Immune recovery vitritis associated with inactive cytomegalovirus retinitis: a new syndrome. Arch Ophthalmol 1998;116:169-75.
23 Zegans ME, Walton RC, Holland GN, et al. Transient vitreous inflammatory reactions associated with combination ntiretroviral therapy in patients with AIDS and cytomegalovirus retinitis. Am f Ophthalmol 1998;125:292-300.

24 Deayton J, Mocroft A, Wilson P, et al. Loss of cytomegalovirus viraemia following highly active antiretroviral therapy in the absence of specific anti-CMV therapy. AIDS 1999;13: 1203-6.

25 Casado JL, Arrizabalaga J, Montes M, et al. Incidence and risk factors for developing cytomegalovirus retinitis in HIV-infected patients receiving protease inhibitor therapy. AIDS 1999;13:1497-501.

26 Tural C, Romeu J, Sirera G, et al. Long-lasting remission of cytomegalovirus retinitis without maintenance therapy in human immunodeficiency virus-infected patients. F Infect Dis 1997;177:1080-83.

27 Vrabec TR, Baldassano VF, Whitcup SM. Discontinuation of maintenance therapy in patients with quiescent cytomegalovirus retinitis and elevated CD4+ counts. Ophthalmology 1998;105:1259-64.

28 Macdonald JC, Torriani FJ, Morse LS, et al. Lack of reactivation of cytomegalovirus retinitis after stopping CMV maintenance therapy in patients with sustained elevations in CD4 T cells in response to highly active antiretroviral therapy. F Infect Dis 1998;177:1182-7.

29 Jabs DA, Bolton SG, Dunn JP, et al. Discontinuing anticytomegalovirus therapy in patients with immune restoration after combination antiretroviral therapy. $A m \mathcal{F}$ Ophthalmol 1998;126:817-22.

30 Whitcup SM, Fortin E, Lindblad AS, et al. Discontinuation of anticytomegalovirus therapy in patients with HIV infection and cytomegalovirus retinitis. $7 A M A$ 1999;282: 1633-7.

31 Torriani FJ, Freeman WR, Macdonald JC, et al. CMV retinitis recurs after stopping treatment in virological and immunological failures of potent antiretroviral therapy. AIDS 2000;14:173-80.

32 Salmon-Céron D, Mazeron M-C, Chaput S, et al. Plasma cytomegalovirus DNA, pp65 antigenaemia and a low CD4 cell count remain risk factors for cytomegalovirus disease in patients receiving highly active antiretroviral therapy. AIDS 2000;14:1041-9. 